\title{
Interdecadal variability of winter precipitation in Southeast China
}

\author{
Ling Zhang $\cdot$ Xiuhua Zhu $\cdot$ Klaus Fraedrich $\cdot$ \\ Frank Sielmann $\cdot$ Xiefei Zhi
}

Received: 6 November 2013/Accepted: 6 January 2014/Published online: 21 January 2014

(C) The Author(s) 2014. This article is published with open access at Springerlink.com

\begin{abstract}
Interdecadal variability of observed winter precipitation in Southeast China (1961-2010) is characterized by the first empirical orthogonal function of the three-monthly Standardized Precipitation Index (SPI) subjected to a 9-year running mean. For interdecadal time scales the dominating spatial modes represent monopole features involving the Arctic Oscillation (AO) and the sea surface temperature (SST) anomalies. Dynamic composite analysis (based on NCEP/NCAR reanalyzes) reveals the following results: (1) Interdecadal SPI-variations show a trend from a dryer state in the 1970s via an increase during the 1980s towards stabilization on wetter conditions commencing with the 1990s. (2) Increasing wetness in Southeast China is attributed to an abnormal anticyclone over south Japan, with northward transport of warm and humid air from the tropical Pacific to South China. (3) In mid-tohigh latitudes the weakened southward flow of polar airmasses induces low-level warming over Eurasia due to stronger $\mathrm{AO}$ by warmer zonal temperature advection. This indicates that $\mathrm{AO}$ is attributed to the Southeast China
\end{abstract}

L. Zhang $(\bowtie) \cdot$ K. Fraedrich $\cdot$ X. Zhi

Key Laboratory of Meteorological Disaster of Ministry of Education, Nanjing University of Information Science and Technology, Nanjing, China

e-mail: ling.zhang@zmaw.de

L. Zhang $\cdot$ K. Fraedrich

Max Planck Institute for Meteorology,

Hamburg, Germany

X. Zhu

KlimaCampus, Hamburg University, Hamburg, Germany

F. Sielmann

Meteorological Institute, Hamburg University,

Hamburg, Germany precipitation increase influenced by circulation anomalies over the mid-to-high latitudes. (4) The abnormal moisture transport along the southwestern boundary of the abnormal anticyclone over south Japan is related to anomalous southeasterlies modulated by the SST anomalies over Western Pacific Ocean; a positive (negative) SST anomaly will strengthen (weaken) warm and humid air transport, leading to abundant (reduced) precipitation in Southeast China. That is both AO and SST anomalies determine the nonlinear trend observed in winter precipitation over Southeast China.

Keywords Precipitation - SPI - Arctic Oscillation . Sea Surface Temperature

\section{Introduction}

South China is located in East Asian Monsoon regions where weather and climate disasters bring frequent damage in winter. For example, in 2005 and 2008, extreme freezing rain and snow in southern China resulted in considerable loss of life. This winter precipitation variability has attracted wide attention. Zhai et al. (2005) showed that winter precipitation has increased significantly over South China in recent decades. Numerous studies reported that precipitation trends over the last half century were accompanied by a temperature increase over southern and eastern China $\mathrm{Hu}$ et al. 2003; Wang et al. 2004; Wang and Zhou 2005; Su et al. 2006; Zhou and Yu 2006; Guo and Ding 2009; Zhi et al. 2010; Wang et al. 2012). In addition, the increasing precipitation is also accompanied by striking decrease of sunshine duration and surface evaporation (Thomas 2000) and decreasing snowfall totals (Gillies et al. 2012). 
One of the active factors for Eurasian winter climate is the Arctic Oscillation (AO) (Thompson and Wallace 2000; Gong et al. 2001). Gong and Wang (2003) found high correlation between $\mathrm{AO}$ and winter precipitation over southern and central China. AO is also highly correlated with East Asian Winter Monsoon (EAWM) (Gong et al. 2001; Wu and Wang 2002; Li and Bates 2007). Furthermore, in winter the AO directly affects surface air temperature (SAT), sea level pressure (SLP), and the East Asian trough (EAT) at $500 \mathrm{hPa}$ over the region north of $35^{\circ} \mathrm{N}$ in East Asia (Gong et al. 2001; Gong and Wang 2003).

The EAWM system is another active component of the global circulation, whose prominent surface feature is characterized by strong northwesterlies along the eastern boundary of the Siberian high $(\mathrm{SH})$ and the East Asian coast. An abnormal EAWM can induce circulation changes over East Asia (Chen et al. 2000; Chou et al. 2009; Zhou 2011). Previous studies have shown that the EAWM variability affects wintertime climate variations over China, Korea, Japan and surrounding regions (Ding 1994; Huang et al. 2003; Chang et al. 2006). Monsoon outbreak is accompanied by rapid southward intrusions of cold air bringing severe weather, such as gales, cooling, frost, rainstorms, freezing rain and serious sandstorms to most areas of East Asia. Zhou and Wu (2010, Zhou 2011) pointed out that the EAWM has an impact on JFM (January-March) rainfall in South China. A weak EAWM corresponds to anomalous southwesterly winds over the South China Sea, which induces anomalous moisture convergence and upward motion thus enhancing rainfall over southern China.

In addition to the atmosphere circulation anomalies, many studies have shown that the tropical sea surface temperature (SST) has a large impact on climate anomalies in East Asia (Wang et al. 2000; Wang and Zhang 2002; Huang et al. 2003; Chou et al. 2009; Xie et al. 2009; Zhou et al. 2010; Zhou and Wu 2010; Feng and Li 2011; Wang et al. 2012), which is also observed in winter (Zhang and Sumi 2002; Wu et al. 2003; Zhou et al. 2010; Zhou and Wu 2010) on decadal-to-interdecadal time scales (Nitta and Yamada 1989; Zhang et al. 1997; Liu 2012). The relationship between the SST anomalies over tropical Pacific and the climate of South China has changed after the late 1970s (Ding et al. 2010; Li et al. 2010; Wang et al. 2012), which is partially associated with the tropical SST patterns shifting from "conventional" ENSO SST to ENSO Modoki-like conditions in recent three decades (Zhang et al. 2011). The extratropical SST also has close relationship with East Asian climate systems (Liu et al. 2007; Wu et al. 2010; Kim et al. 2013). Arctic SST anomalies excite geopotential height anomalies over northern Eurasian continent with impact on the central SH (Wu et al. 2010). And Kim et al. (2013) study of the combined effect of ENSO and Pacific Decadal Oscillation (PDO) on the EAWM; they note that
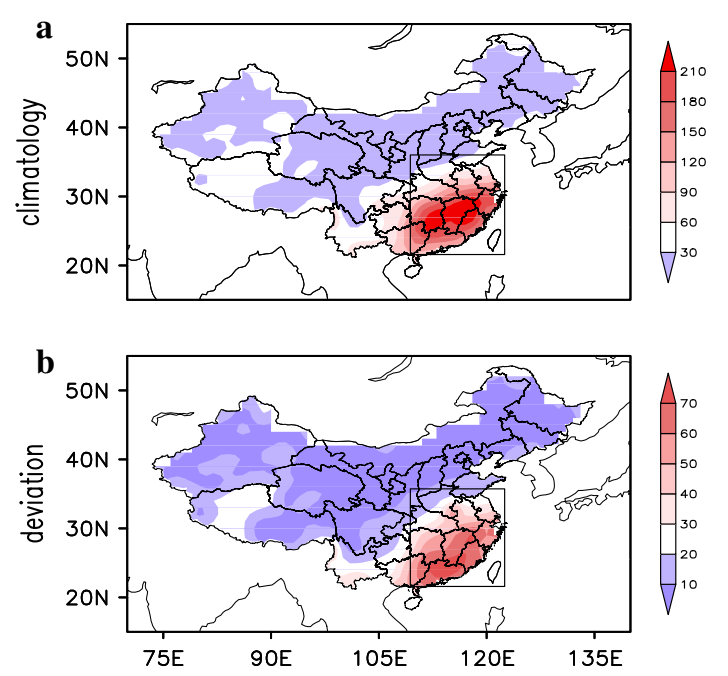

Fig. 1 Winter (December-February) precipitation (mm/year) for 1962-2010: a mean and b standard deviation. Rectangle shows region of analysis (Southeast China)

when ENSO and PDO are in phase, a negative relationship between ENSO and EAWM is significantly intensified.

Since winter precipitation reveals both interdecadal (Zhai et al. 2005) and interannual (Zhou 2011) patterns of variability, the interaction with large scale circulation systems may depend on the different time scales. There is abundant rainfall in southeastern China exceeding $90 \mathrm{~mm} /$ year with maximum values exceeding $210 \mathrm{~mm}$ (the marked region in the Fig. 1a), whereas in any other region mean precipitation is below $60 \mathrm{~mm}$ in winter. The distribution of the winter to winter variance shows a similar pattern, with large amplitudes in the Southeast (Fig. 1b) indicating higher probability of rainfall extremes. In this paper we focus on the interdecadal variability of southeastern China covering $102.5^{\circ} \mathrm{E}-$ $122.5^{\circ} \mathrm{E}$ and $20^{\circ} \mathrm{N}-35^{\circ} \mathrm{N}$ (rectangle region in Fig. 1) where high quality data from 232 stations are available, and our aim is to identify the relevant large-scale atmospheric and oceanic flow patterns and mechanisms. The paper is structured as follows: data and methods are described in Sect. 2; the variability in terms of precipitation and atmospheric circulation in East Asian regions are shown in Sect. 3; interdecadal variability of precipitation in Southeast China and associated circulation anomalies are presented in Sect. 4; and the conclusion is presented in Sect. 5 with an outlook given on climate change related issues.

\section{Data and methods of analysis}

\subsection{Data}

Monthly observed precipitation from 1961 to 2010 is provided by the National Meteorology Information Center, 
China Meteorological Administration (CMA). Most stations have been established in the $1950 \mathrm{~s}$, but there are many missing data in this period, therefore, we consider only 573 stations for the entire China spanning from 1961 to 2010 , from which 232 stations available are analyzed for southeastern China (marked in Fig. 1). SLP, geopotential height, specific humidity and air temperature data are taken from NCEP/NCAR reanalysis dataset. Global SST is from the Hadley Center Global Sea Ice and Sea Surface Temperature (HadISST, dataset version 1.1). Winter (December, January and February) averages are analyzed.

\subsection{Methods}

Standardized Precipitation Index (SPI): The observed rainfall data used in this study is subjected to a drought and wetness assessment based on the SPI (McKee et al. 1993; Bordi and Sutera 2001; Keyantash and Dracup 2002; Bordi et al. 2004; Bordi et al. 2009). The SPI is a suitable index for comparing regions or watersheds under different climate conditions and provides a useful measure for drought/ wetness monitoring by describing water deficit on meteorological, agricultural and hydrological time scales. The total precipitation over a specific period (for example: 1 , 3 months and 2 years) is assumed as a random variable fitting Gamma distribution (Guttman 1999) and then transformed through an equal-probability transformation into a normal distribution. According to Abramowitz and Stegun (1965), the approximation is,

$$
\begin{aligned}
& S P I=-\left(t-\frac{c_{0}+c_{1} t+c_{2} t^{2}}{1+d_{1} t+d_{2} t^{2}+d_{3} t^{3}}\right) \\
& \text { for } \quad 0<H(x) \leq 0.5 \\
& S P I=+\left(t-\frac{c_{0}+c_{1} t+c_{2} t^{2}}{1+d_{1} t+d_{2} t^{2}+d_{3} t^{3}}\right) \\
& \text { for } \quad 0.5<H(x) \leq 1
\end{aligned}
$$

where

$$
\begin{aligned}
& t=\sqrt{\ln \left(\frac{1}{(H(x))^{2}}\right)} \text { for } \quad 0<H(x) \leq 0.5 \\
& t=\sqrt{\ln \left(\frac{1}{(1-H(x))^{2}}\right)} \text { for } 0.5<H(x) \leq 1
\end{aligned}
$$

with following constants $c_{0}=2.515517, c_{1}=0.802853$, $c_{2}=0.010328, \quad d_{1}=1.432788, \quad d_{2}=0.189269, \quad$ and $d_{3}=0.0001308$. And $H(x)$ is cumulative probability.

Therefore, SPI is derived by comparing the cumulative rainfall for a particular station over a specific time interval with the average cumulative precipitation for that same time interval over the entire length of the record. The classification of SPI values (Bordi and Sutera 2001) are shown as follow,

\begin{tabular}{ll}
\hline SPI value & Drought category \\
\hline 2.00 and above & Extremely wet \\
1.50 to 1.99 & Very wet \\
1.00 to 1.49 & Moderately wet \\
-0.99 to 0.99 & Near normal \\
-1.00 to -1.49 & Moderately dry \\
-1.50 to -1.99 & Severely dry \\
-2.00 and less & Extremely dry \\
\hline
\end{tabular}

In this study, we calculate SPI-3 for February to consider the cumulative effects of precipitation of the three core winter-months (December, January and February). Note that SPI-3 for February characterizes the standardized accumulated rainfall total of all three winter months (and not merely February).

EOF analysis: The SPI-3 is subject to the empirical orthogonal function (EOF, Lorenz 1956; Kim and Wu 1999) analysis to identify its main spatial and temporal variability. It has been first applied to the original SPI-3 fields; later to highlight the interdecadal signal in SPI-3, the EOF analysis is applied to a 9-year running mean of the SPI-3.

Linear regression and composite analysis: To highlight the signal in wind fields akin to the interdecadal component of SPI-3 and Western Pacific SST, wind fields are first linearly regressed on to the interdecadal component of SPI3 and Western Pacific index (WPI). Then composite analysis is applied to the reconstructed wind fields from linear regression, examining associated ideal circulation anomalies of anomalous precipitation in Southeast China on interdecadal time scales. And based on the original fields (wind, temperature and SST), the possible causes of the interdecadal variations of southeast China precipitation are analyzed through composite analysis and employing the student's $t$ test.

\section{Southeast China precipitation variability}

The variability of regionally averaged winter mean precipitation in the key study region $\left(102.5^{\circ} \mathrm{E}-122.5^{\circ} \mathrm{E}, 20^{\circ} \mathrm{N}-\right.$ $35^{\circ} \mathrm{N}$ ) is shown in Fig. 2 (dashed). In order to analyze the relationship between Southeast China precipitation and the assumed factors influencing the Eurasian winter climate, the AO and the EAWM are considered in the first instance (Fig. 2). The EAWM is described by an intensity index, 

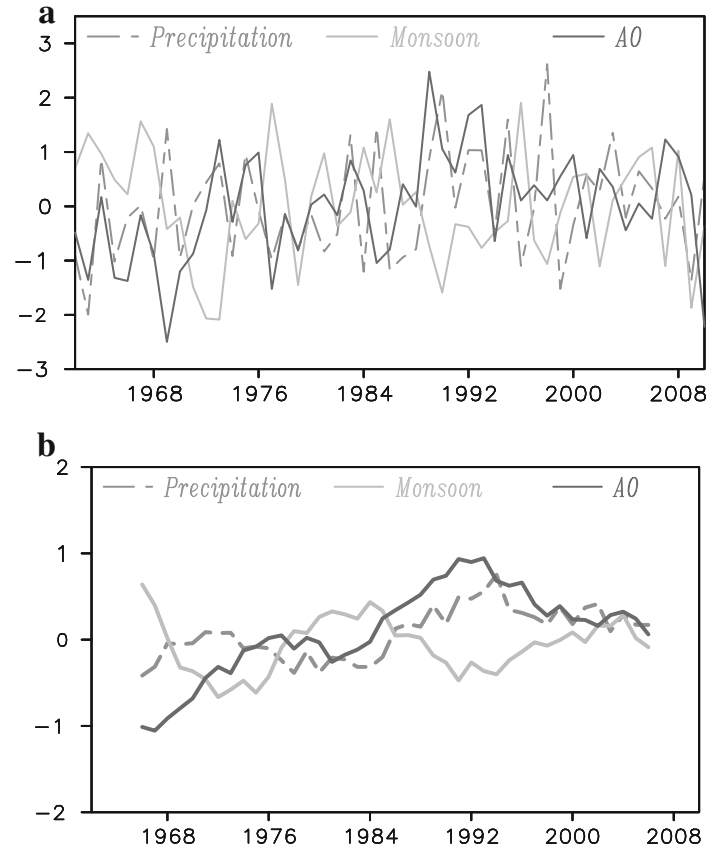

Fig. 2 Time series (a) and 9-year running means (b) of Southeast China winter precipitation (dashed), EAWM index (light gray), and $\mathrm{AO}$ index (dark gray). All time series have been normalized

which measures the zonal SLP differences $\left(110^{\circ} \mathrm{E}-\right.$ $160^{\circ} \mathrm{E}$, sum from $20^{\circ} \mathrm{N}-70^{\circ} \mathrm{N}$ ) (Shi et al. 1996; Wu and Wang 2002). The AO is defined as the first principal component of the EOF analysis of the Northern Hemisphere SLP field. To highlight the interdecadal variability, a 9-year running mean is applied to all indices (Fig. 2b). A positive trend is clearly visible in precipitation in Southeast China and the AO index; after around 1990, the system settles in a relatively stable condition. The correlation of the EAWM (AO) index with winter precipitation in Southeast China reveals a significant negative (positive) relationship. As the EAWM index trend is not significant, the subsequent analysis focuses on the $\mathrm{AO}$ as the dominating factor to explain the possible causes of Southeast China precipitation trend.

East China is located between the ridge in the west of Lake Baikal and the trough in the east of northeastern China, where northwesterlies prevail (Fig. 3). These northwesterlies (at 1,000 hPa) extend further southward along the East Asian coast and are tightly linked with the SH (not shown). In contrast, further southward and near the surface, the south coast of China is governed by northeasterlies and a weak anticyclone off the coast (Fig. 3); the south is influenced by tropical and subtropical climate systems. In the following analysis, the associated circulation systems from mid-and-high latitudes and mid- and low latitudes are both considered to further study the factors for the interdecadal variability of Southeast China precipitation.

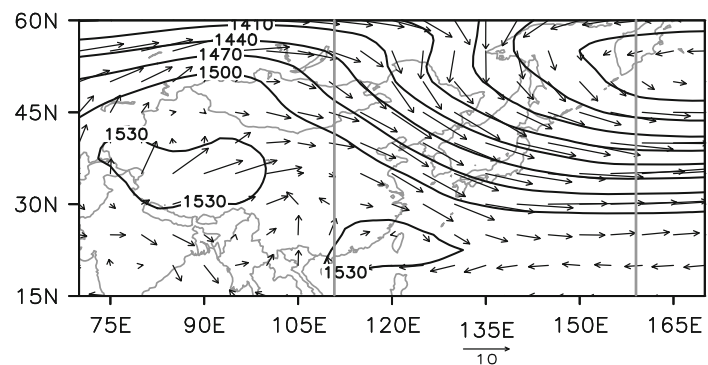

Fig. 3 Winter (December-February) geopotential height (gpm, contour) and horizontal wind (m/s, vector) at $850 \mathrm{hPa}$ for 1962-2010. Straight lines denote two meridian lines of $110^{\circ} \mathrm{E}$ and $160^{\circ} \mathrm{E}$

\section{Interdecadal variations of precipitation and associated circulation influences}

\subsection{Interdecadal precipitation variability}

The temporal and spatial features of the cumulated winter precipitation in Southeast China are suitably characterized by the first EOF of the SPI-3 index, which explains $36.8 \%$ of the total variance showing a uniform spatial pattern over South China (Fig. 4a). Note that SPI-3 (for February) comprises all three winter months (December through February). The corresponding time coefficient demonstrates both interannual and also long-term variability (Fig. 4b). The long-term variability of the SPI-3 is highlighted by a 9 -year running mean applied at each station, after which the EOF analysis is conducted. The first leading EOF pattern (explaining $42.2 \%$ of the variance) is characterized by a monopole. Its maximum loading occurs along $30^{\circ} \mathrm{N}$ and in the northeastern part of the key region (Fig. 4c); the corresponding PC-1 represents an interdecadal South China Drought Index which clearly exhibits interdecadal variability (Fig. 4d), showing that, before the 1980s, the winter precipitation in Southeast China is below the climate mean and attains higher values after the 1990s separated by a 10 year transition phase in the 1980s. In the following, we select the periods 1962-1976 and 1988-2002 to provide composites contrasting dry and wet winters, which is supplemented by regression analysis.

\subsection{Atmospheric circulation}

The circulation patterns on interdecadal scale are analyzed by linear regression and composites. In order to highlight the circulation associated with the interdecadal variability of southeast China precipitation, the typical circulation patterns on the interdecadal scale are extracted by a linear regression between the interdecadal South China drought index PC-1 (Fig. 4d) and the horizontal wind fields, yielding a relative anticyclone over South Japan during the wet period (Fig. 5a, b); that is, south-easterlies prevail 
Fig. 4 First EOF (a, c) and first principal components $(\mathbf{b}, \mathbf{d})$ of original February SPI-3 (a, b) and interdecadal variability derived from the filter (9-year running mean) February SPI-3 $(\mathbf{c}, \mathbf{d})$ in Southeast China (highlighted rectangular region in Fig. 1)
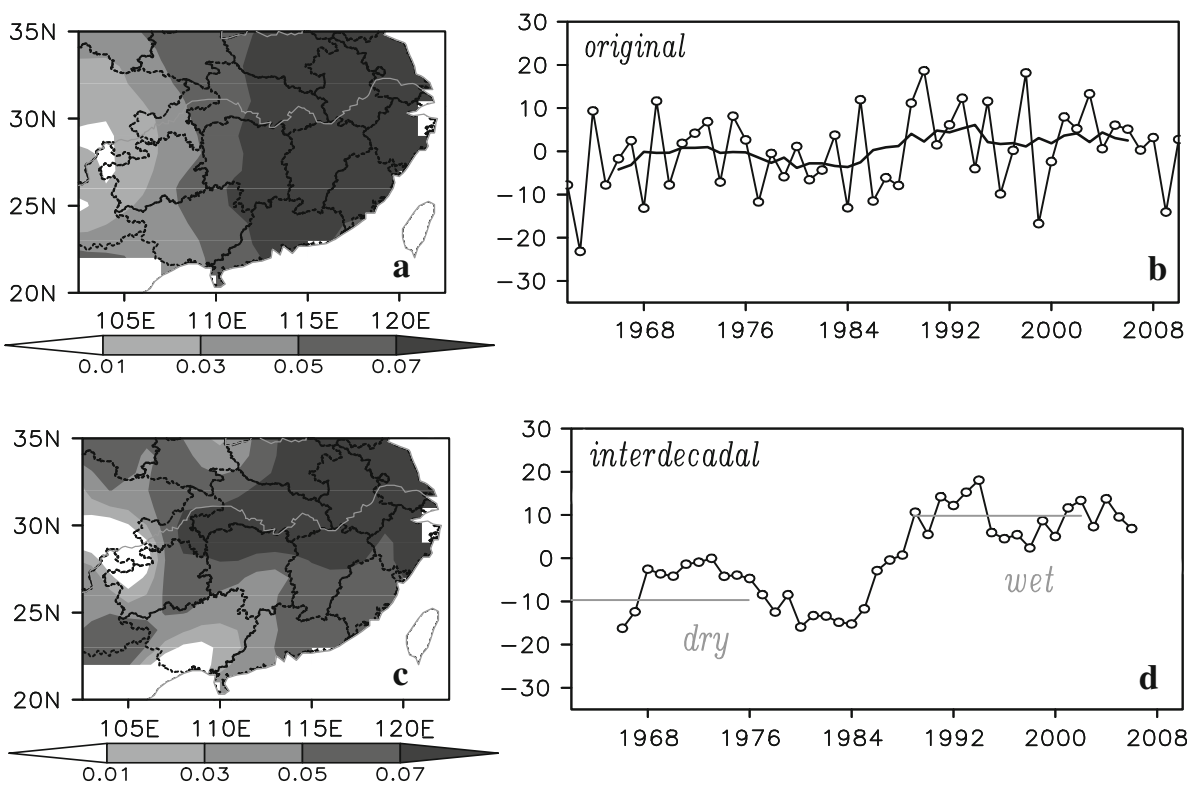
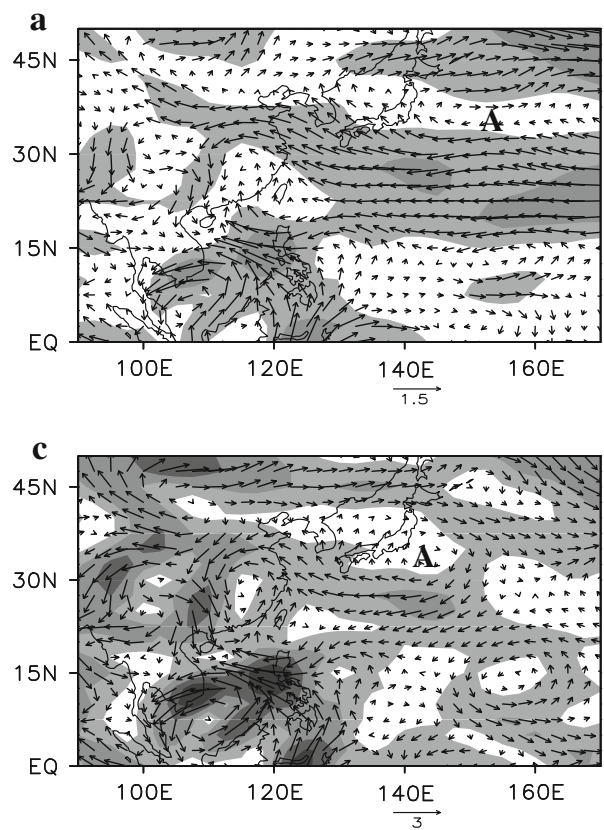

Fig. 5 Difference fields of wet minus dry periods: response variables of horizontal (u, v) flow direction (arrows) and amplitude (shading: light $<1.2 \mathrm{~m} / \mathrm{s}$, dark $>1.2 \mathrm{~m} / \mathrm{s}$, and intermediate) derived from regression with interdecadal Southeast China drought index PC-1 of

along the east coast (at $925 \mathrm{hPa}$, Fig. 5a) associated with a northward moisture flux anomaly from the western Pacific across the east coast of China towards Southeast China. The linear response of the wind field to the interdecadal drought index PC-1 (of the SPI-3) is amplified by linear regression and the regressed fields show significance for the whole area (95\% student $t$ test), as regression performs a time-coordinate transformation of the time series of the
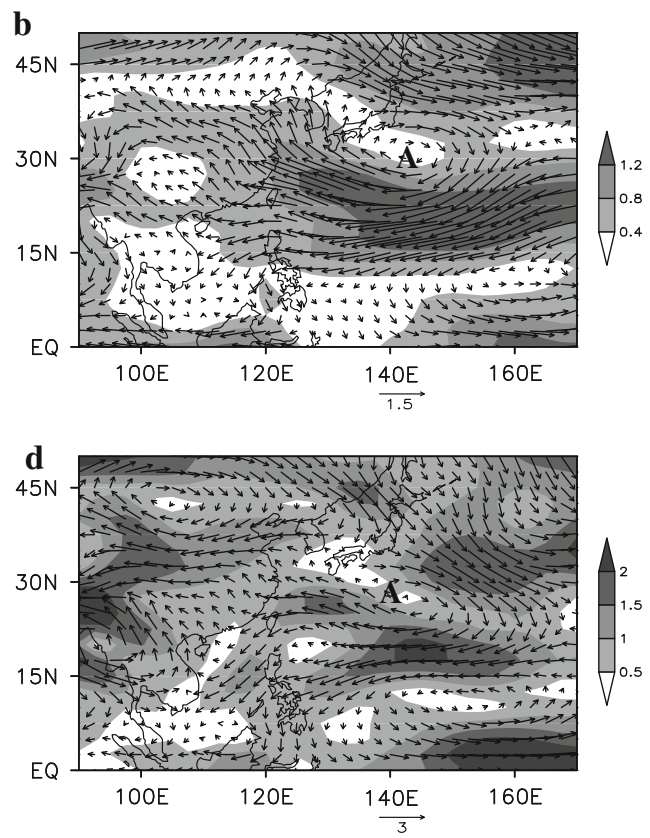

SPI-3 (Fig. 4d) at a $925 \mathrm{hPa}$ and b $500 \mathrm{hPa}$; unregressed horizontal wind directions (arrows) and their amplitudes (shading: light $<1.5 \mathrm{~m} / \mathrm{s}$, dark $>1.5 \mathrm{~m} / \mathrm{s}$, and intermediate) at c $925 \mathrm{hPa}$ and $\mathbf{d}$ at $500 \mathrm{hPa}$ (" $A$ " represents anticyclone)

wind field creating an idealized flow pattern, which explains $20-30 \%$ of the year to year variance in the area of interest $\left(110^{\circ} \mathrm{E}-160^{\circ} \mathrm{E} ; 15^{\circ} \mathrm{N}-45^{\circ} \mathrm{N}\right)$.

This regression pattern is similar to the wet (1988-2002) minus dry (1962-1976) composites of the original wind fields at 925 and $500 \mathrm{hPa}$. Figure 5c, d show an anomalous relative anticyclone (cyclone) over South Japan (southeast China), indicating southeastern China is under the reign of 
Fig. 6 a Zonally averaged zonal wind $(\mathrm{m} / \mathrm{s})$ in the wet and dry periods with standard deviations (blue shading); b meridional moisture flux differences (wet minus dry periods mean) at $925 \mathrm{hPa}[(\mathrm{mg}) /$ $(\mathrm{kg} \mathrm{s})]$ with $95 \%$ level of significance (shading)
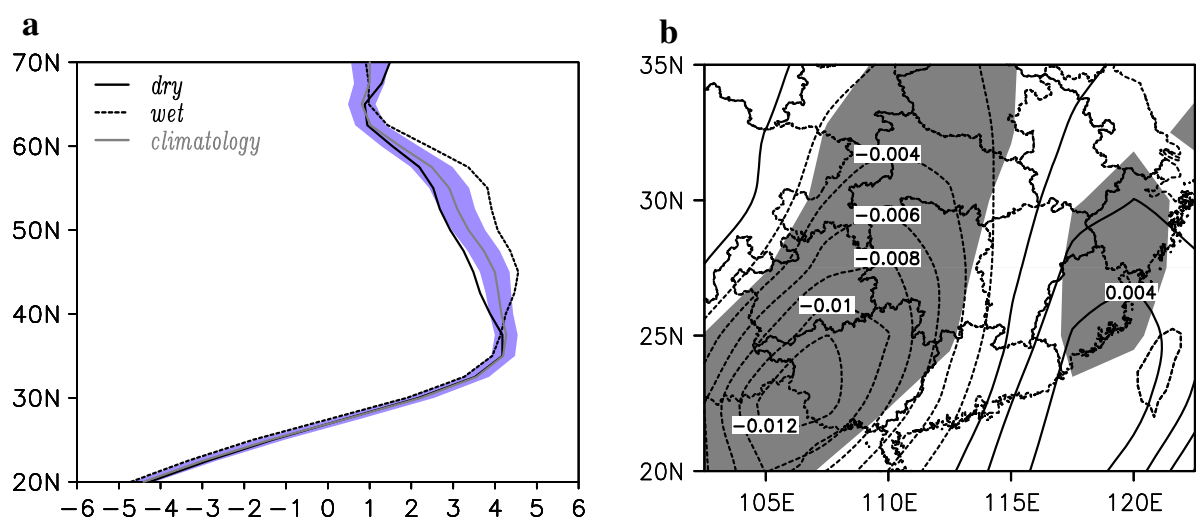

south-westerly and south-easterly anomalies at $925 \mathrm{hPa}$ during the wet period (Fig. 5c). The anticyclone over South Japan can also be captured in the mid-troposphere (Fig. 5d).

Figure 6a shows the averaged global zonal wind during wet and dry periods at $925 \mathrm{hPa}$ compared to the grey line representing the global zonal wind climatology. The wet (dry) period is characterized by significantly (exceeding one standard deviation) stronger (weaker) zonal westerlies over the mid-high latitudes; especially in the $40-60^{\circ} \mathrm{N}$ latitude band. Meanwhile, the meridional moisture flux shows positive (negative) anomalies over Southeast China at $925 \mathrm{hPa}$ during the wet (dry) period (Fig. 6b). That is, during the wet period, the weaker northerlies (Fig. 5c) are associated with anomalous enhanced northward moisture flux along the east coast (shown in Fig. 6b for the $925 \mathrm{hPa}$ level). This flow pattern provides more moisture for Southeast China from the south towards the east coast of China favoring enhanced rainfall in the southeast China. The opposite holds for the dry period.

In summarizing, the interdecadal variability of the winter precipitation in Southeast China is characterized by an abnormal anticyclone over South Japan and accompanied by a northward moisture transport anomaly. Compared with the meridional wind fields in Southeast China, the signal of the zonal wind field anomaly shows significance at lower levels.

\subsection{AO influences}

The abnormal anticyclone over South Japan plays an important role in the interdecadal variability of Southeast China precipitation by weakening the trough over East Asia (Fig. 2) and decreases the meridional circulation which, in turn, determines the positive trend of precipitation in Southeast China.

Why did the abnormal anticyclone appear after the 1990's? As shown in Fig. 2, AO and Southeast China precipitation show similar increasing trends. The SLP
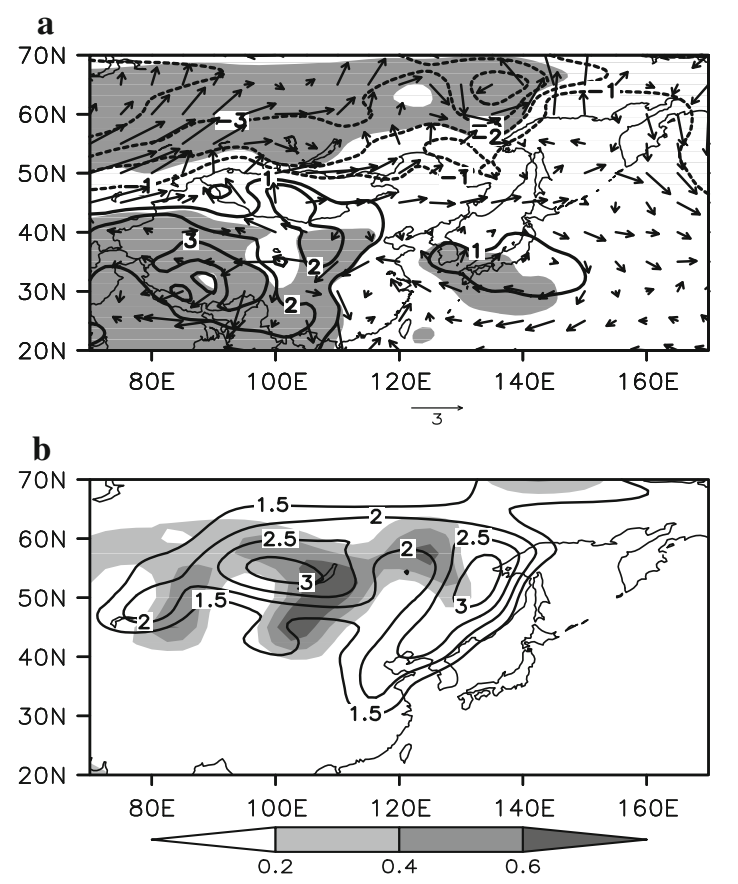

Fig. 7 Difference fields of wet minus dry periods: a sea level pressure (SLP) (hPa; negative/positive: dash/full lines) and horizontal winds (m/s; arrows). Shaded areas are statistically significant at $95 \%$ confidence level for SLP; $\mathbf{b}$ temperature (full lines) and temperature advection by zonal-mean of zonal component of abnormal wind vectors (shading)

composite exhibits a characteristic AO-related seesaw pattern (Fig. 7a). The AO index has a significant positive relationship with the zonal wind over mid-to-high latitudes (not shown), which is also evident from the horizontal wind field composite (Fig. 7a). The abnormal zonal westerlies in the $40-50^{\circ} \mathrm{N}$ latitude band accompany the increasing $\mathrm{AO}$ index.

In addition to the close relationship between $\mathrm{AO}$ and the circulation anomalies, AO is also positively correlated with the near SAT over East Asia north of $35^{\circ} \mathrm{N}$ (Gong et al. 2001; Wu and Wang 2002; Gong and Wang 2003). We observe this positive relation on the interdecadal time scale 
extending up to mid-tropospheric levels (not shown). During wet periods and increasing $\mathrm{AO}$, abnormal warming is observed over the continental regions (contour line in Fig. 7b), which is associated with the AO (Thompson and Wallace 2000, Deweaver and Nigam 2000). Thompson and Wallace (2000) proposed that the lower tropospheric temperature changes are AO-covariant and forced by horizontal temperature advection due to zonal eddy flow. Much of the temperature pattern as demonstrated by Deweaver and Nigam (2000) is due to zonal onshore and offshore advection $\left(-\bar{u}_{a} \frac{\partial T_{c}^{*}}{\partial x}\right.$, where $\bar{u}_{a}$ represents anomalous zonalmean zonal wind and $T_{c} *$ is the stationary eddy part of the climatological temperature field). The advection of the climatological temperature field by the anomalous zonalmean zonal wind $-\bar{u}_{a} \frac{\partial T_{c}^{*}}{\partial x}$ (shaded in Fig. $7 \mathrm{~b}$ ) shows a pattern, which is similar to that of the observed temperature changes (Fig. 7b). This demonstrates that interdecadal AO variability determines the positive temperature change over Eurasia by zonal mean zonal flow anomalies inducing temperature change by advection.

Subsequently, this warming of the lower troposphere reduces the pressure over the Eurasian continent which, in turn, weakens the northerlies due to weaker zonal land-sea pressure gradients. Thus abnormal southerlies can transport more moisture to the mainland and enhance the precipitation over Southeast China.

In summarizing, the observed interdecadal $\mathrm{AO}$ variability affects Southeast China precipitation anomalies through the following mechanisms: After the 1990's, enhanced winter precipitation is observed in Southeast China (associated with larger moisture supply) which is supported by the following processes:

1. A strengthened AO leads to continental warming. Forced by zonal temperature advection, higher air temperature occurs over the mid- and high latitudes of East Asia.

2. A stronger southerly flow anomaly, due to weaker zonal land-sea pressure gradients which are induced by warming in the northern part of East Asia.

3. The suppression of meridional exchange by strongerthan-normal westerlies and, in particular, of the northerlies along eastern China.

This interaction of mechanisms is effective on interdecadal time scales, and shows how the AO contributes to the observed higher winter rainfall in Southeast China after the 1990s.

\subsection{SST influence}

In the preceding Sect. 4.3, the general circulation anomalies over mid-to-high latitudes are investigated as main factors. But, due to the geographical location of Southeast China, precipitation variability over these regions is influenced by the interaction between mid-high and mid-low latitudes. One important circulation anomaly is the midlatitude northwestward moisture flux from Western Pacific to Southeast China, which contributes to the nonlinear increasing trend of Southeast China precipitation. Possible causes of this anomalous moisture channel formation can be attributed to SST anomalies as demonstrated by regression and composite analyses.

The SST difference fields between wet and dry periods (Fig. 8) indicate that during wet periods (with $95 \%$ significant confidence) positive SST anomalies occur over mid-low latitudes of the Western Pacific and in the Indian Ocean. Two SST indices are defined as regional SST averages: WPI $\left(120^{\circ}-170^{\circ} \mathrm{E}, 20^{\circ}-40^{\circ} \mathrm{N}\right)$ and Indian Ocean index (IOI, $\left.40^{\circ}-110^{\circ} \mathrm{E},-20^{\circ}-20^{\circ} \mathrm{N}\right)$, respectively. The interdecadal variability (9-year running mean) of both WPI and IOI show increasing trends during the last 50 years (Fig. 9a, b). For the Western Pacific the SST is warmer after the late 1980's, and for Indian Ocean the SST warming appears a few years earlier (in the 1980's). The horizontal wind fields regressed onto the interdecadal South China drought index PC-1 (Fig. 4d) of February SPI3 show that, during the Indian Ocean warming (wet period), tropospheric easterly anomalies prevail over the North Indian Ocean (not shown), which is unfavorable for transporting warm and moist air to mainland China, so that the warming of the Indian Ocean may not influence the Southeast China precipitation directly. However, tropospheric southeasterly anomalies over the western Pacific enhance warm and humid air transport to the east coast of China. That is, the mid-low latitude warming of the western Pacific provides the main contribution to the anomalous easterlies' moisture supply. The differences (warm minus cold) of horizontal wind fields, when regressed with WPI (grey line in Fig. 9a), indicate anomalous tropospheric northeasterlies over the Western Pacific and an abnormal anticyclone south of Japan. Warming over midto-low latitudes decreases the SST gradients between tropical and mid-to-low latitudes of the western Pacific (Fig. 8), which provides an anti-Hadley circulation (anomaly) over western Pacific (Fig. 10). The northerlies (southerlies) prevail along South China Sea and western Pacific with divergence (convergence) over tropical regions and convergence (divergence) over east coast of China and mid-low latitude of western Pacific in the lower (upper) tropospheric level. These lower tropospheric air flow anomalies bring abundant warm and moist air from the western Pacific across the East and South China Sea to Southeast China leading to increasing precipitation.

In summary, a wetter period on interdecadal time scales reveals SST anomalies over the Western Pacific to be 


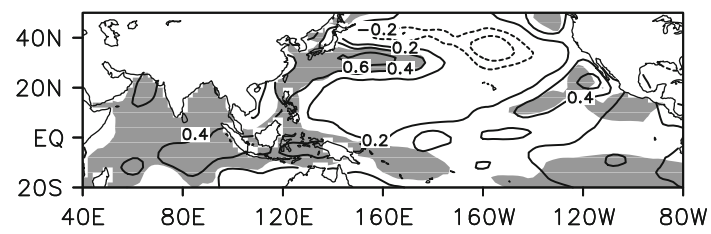

Fig. 8 Difference fields of wet minus dry periods: sea surface temperature (SST) (K; negativelpositive: dash/full lines). Shaded areas are statistically significant at $95 \%$ confidence level

warmer than normal, which supports warm moist air being transported into Southeast China through the anomalous south-easterlies prevailing over Southeast China. That is, on the interdecadal scales, SST anomalies over Western Pacific play an active role in regulating the strength of winter precipitation in Southeast China.

\section{Summary and outlook}

Winter precipitation variability of Southeast China on interdecadal time scales involves the EAWM, the AO, and the SST by the associated moisture flow and temperature advection. All analyses are performed with both NCEP/ NCAR and ERA-40 reanalysis datasets, but since the atmosphere circulation features are similar, only results from NCEP/NCAR reanalysis dataset are presented.

The Standardized Precipitation Index (SPI of 3 months) could capture the winter wetness and dryness interdecadal variability in Southeast China by employing a 9-year running mean. The first EOF of the interdecadal components of SPI-3 describes $42.2 \%$ of the respective space-time variabilities. The associated principal components serve as indices to characterize wetness and drought variability and its relation with the large scale atmospheric circulation patterns governing the winter climate of East Asia. The following results are obtained:

1. On interdecadal scales, the dominating spatial wetness and drought intensity pattern is uniform in Southeast China; its temporal variability increases following a positive trend; that is, SPI-3 indices (dry) are small before the 1980's, increasing during the 1980's and stabilizing at larger values after the 1990's.

2. The circulation anomalies over the mid- and high latitudes of East Asia play an important role in the trend of Southeast China precipitation. The increased precipitation in Southeast China after 1980s is a result of the weakened northerlies over East China, which is caused by low-level warming over the high-latitude Eurasian continent due to strengthening of the AO after 1980s. This underlines the important role of the AO for interdecadal variability of wetness and dryness in Southeast China.

3. Except for the circulation anomaly over the mid-tohigh latitudes, the anomalies over the mid-to-low latitudes also contribute to the interdecadal variability of Southeast China precipitation. The composites of the atmospheric circulation fields indicate that southeasterlies prevail over the eastern coast of China. Wetness (dryness) is associated with stronger (weaker) than normal moisture transport from the ocean. The
Fig. 9 Time series of SST (K; black lines): a Western Pacific (WPI); b Indian Ocean (IOI). 9-year running means are give in grey lines
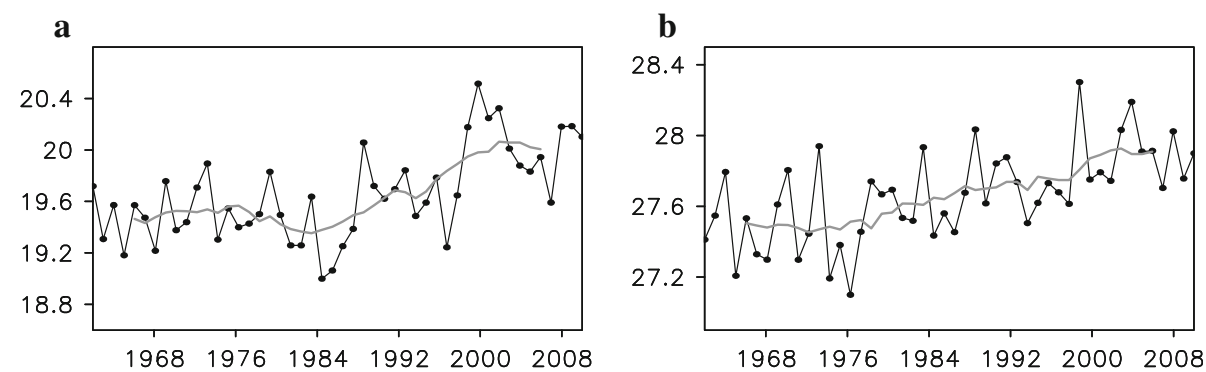
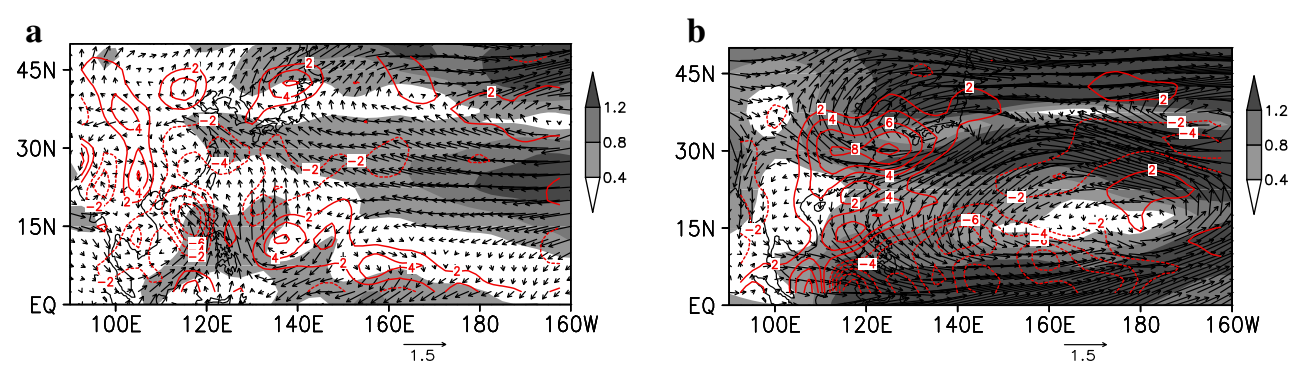

Fig. 10 Difference fields of wet minus dry periods: response variables u, v (m/s; arrows), their amplitude (m/s; shading) and divergence (red lines) derived from regression with 9-year running mean of WPI (grey line in Fig. 9a) at a $925 \mathrm{hPa}$; b $200 \mathrm{hPa}$ 
SST over the Western Pacific is warmer (cooler) than normal due to the southeasterly flow anomalies through an abnormal anti-Hadley circulation over the Western Pacific. Hence, SST anomalies over Western Pacific are important for interdecadal variability of winter precipitation in Southeast China.

In addition to SST anomalies and the $\mathrm{AO}$, the $\mathrm{SH}$ as one of major circulation systems has also been examined. Composite analysis shows that $\mathrm{SH}$ anomalies are not significant. Removing the possible effect of winter $\mathrm{AO}$ on the SLP field shows that abnormal SH signals are not remarkable; that is, the $\mathrm{SH}$ variability does not appear to provide obvious anomalies. According to a study of Chang and $\mathrm{Lu}$ (2012), during the three recent decades the SH had an out-of-phase relationship within the winter season between November and December/January. This relationship may become prevalent, if the positive AO pattern occurs more frequently under global warming. The intraseasonal variability of $\mathrm{SH}$ is so pronounced that an intensity change is masked and does not show remarkable anomalies during the DJF mean.

The observational analyses have given insight into the underlying circulation mechanisms and provided information for testing the performance of global climate models to verify their ability to simulate large scale dynamics in a climate mean sense, in particular, its variability on different time scales. This will be subject of forthcoming research.

Acknowledgments Support is acknowledged by National Basic Research Program "973” of China (2012CB955200), Key Laboratory of Meteorology Disaster of Ministry of Education (KLME1102), Priority Academic Program Development (PAPD) of Jiangsu Higher Education Institutions (LZ, XFZ), by Max Planck Fellowship (LZ, KF), by the South China Sea Institute of Oceanology (SCSIO, XHZ), and Hamburg University (FS).

Open Access This article is distributed under the terms of the Creative Commons Attribution License which permits any use, distribution, and reproduction in any medium, provided the original author(s) and the source are credited.

\section{References}

Abramowitz M, Stegun IA (1965) Handbook of mathematical functions. Dover, p 1046

Bordi I, Sutera A (2001) Fifty years of precipitation: some spatially remote teleconnnections. Water Resour Manag 15:247-280

Bordi I, Fraedrich K, Jiang JM, Sutera A (2004) Spatio-temporal variability of dry and wet periods in eastern China. Theor Appl Climatol 79:81-91

Bordi I, Fraedrich K, Sutera A (2009) Observed drought and wetness trends in Europe: an update. Hydrol Earth Syst Sci 13:1519-1530

Chang CP, Lu MM (2012) Intraseasonal predictability of siberian high and east asian winter monsoon and its interdecadal variability. J Clim 25:1773-1778
Chang CP, Wang Z, Hendon H (2006) The Asian winter monsoon. In: Wang B (ed) The Asian monsoon. Praxis, Berlin, pp 89-127

Chen W, Graf HF, Huang RH (2000) The interannual variability of East Asian winter monsoon and its relation to the summer monsoon. Adv Atmos Sci 17:48-60

Chou C et al (2009) El Niño impacts on precipitation in the western North Pacific-East Asian sector. J Clim 22:2039-2057

Deweaver E, Nigam S (2000) Zonal-eddy dynamics of the north Atlantic oscillation. J Clim 13:3893-3914

Ding YH (1994) Monsoon over China. Kluwer, Dordrecht, p 420

Ding RQ, Ha K, Li JP (2010) Interdecadal shift in the relationship between the East Asian summer monsoon and the tropical Indian Ocean. Clim Dyn 34:1059-1071

Feng J, Li J (2011) Influence of El Niño Modoki on spring rainfall over south China. J Geophys Res 116:D13102. doi:10.1029/ 2010JD015160

Gillies RR, Wang SY, Huang WR (2012) Observational and supportive modeling analyses of winter precipitation change in China over the last half century. Int J Climatol 32:747-758

Gong DY, Wang SW (2003) Influence of Arctic Oscillation on winter climate over China. J Geograph Sci 13:208-216

Gong DY, Wang SW, Zhu JH (2001) East Asian winter monsoon and Arctic Oscillation. Geophys Res Lett 28(10):2073-2076

Guo YJ, Ding YH (2009) Long-term free-atmosphere temperature trends in China derived from homogenized in situ radiosonde temperature series. J Clim 22:1037-1051

Guttman NB (1999) Accepting the standardized precipitation index: a calculation algorithm. J Water Resour Assoc 35:311-322

Hu ZZ, Yang S, Wu R (2003) Long-term climate variations in China and global warming signals. J Geophys Res 108(D19):4614. doi:10.1029/2003JD003651

Huang RH, Zhou LT, Chen W (2003) The progresses of recent studies on the variabilities of the East Asian monsoon and their causes. Adv Atmos Sci 20:55-69

Keyantash J, Dracup JA (2002) The quantification of drought: an evaluation of drought indices. Bull Am Meteorol Soc 83:1167-1180

Kim KY, Wu QA (1999) A comparison study of EOF techniques: analysis of nonstationary data with periodic statistics. J Clim 12(1):185-199

Kim JW, Yeh SW, Chang EC (2013) Combined effect of El NiñoSouthern Oscillation and Pacific Decadal Oscillation on the East Asian winter monsoon. Clim Dyn. doi:10.1007/s00382-013$1730-\mathrm{z}$

Li S, Bates G (2007) Influence of the Atlantic multi decadal oscillation on the winter climate of East China. Adv Atmos Sci 24:126-135

Li JP et al (2010) Can global warming strengthen the East Asian summer monsoon? J Clim 23:6696-6705

Liu ZY (2012) Dynamics of interdecadal climate variability: a historical perspective. J Clim 25:1963-1995

Liu ZY, Liu Y, Wu LX, Jacob R (2007) Seasonal and long-term atmospheric responses to reemerging North Pacific Ocean variability: a combined dynamical and statistical assessment. J Clim 20:955-980

Lorenz EN (1956) Empirical orthogonal function and statistical weather prediction. Technical report, Statistical forecast project report 1, Department of Meteo, MIT, 49

McKee TB, Doesken NJ, Kleist J (1993) The relationship of drought frequency and duration to time scales. In: Proceedings of the 8th conference on applied climatology, 17-22 January, Anaheim, CA, American Meteorological Society, Boston, MA, 179-184

Nitta T, Yamada S (1989) Recent warming of tropical sea surface temperature and its relationship to the Northern Hemisphere circulation. J Meteorol Soc Jpn 67:375-383 
Shi N, Lu J, Zhu Q (1996) East Asian winter/summer monsoon intensity indices with their climatic change in 1873-1989. J Nanjing Inst Meteorol 19(2):168-176 (in Chinese)

Su BD, Jiang T, Jin WB (2006) Recent trends in observed temperature and precipitation extremes in the Yangtze River basin China. Theor Appl Climatol 83:139-151

Thomas A (2000) Spatial and temporal characteristics of potential evapotranspiration trends over China. Int J Climatol 20:381-396

Thompson DWJ, Wallace JM (2000) Annular modes in the extratropical circulation, part I: month-to-month variability. J Clim 13(5):1000-1016

Wang B, Zhang Q (2002) Pacific-East Asian teleconnection. Part II: how the Philippine Sea anomalous anticyclone is established during El Nino development. J Clim 15:3252-3265

Wang Y, Zhou L (2005) Observed trends in extreme precipitation events in China during 1961-2001 and the associated changes in large-scale circulation. Geophys Res Lett 32:L09707. doi:10. 1029/2005GL022574

Wang B, Wu RG, Fu XH (2000) Pacific-East Asian teleconnection: how does ENSO affect East Asian Climate? J Clim 13:1517-1536

Wang S, Zhu J, Cai J (2004) Interdecadal variability of temperature and precipitation in China since 1880. Adv Atmos Sci 21:307-313

Wang X, Wang DX, Zhou W, Li CY (2012) Interdecadal modulation of the influence of La Niña events on mei-yu rainfall over the Yangtze River valley. Adv Atmos Sci 29(1):157-168

Wu BY, Wang J (2002) Winter Arctic Oscillation, Siberian High and East Asian winter monsoon. Geophys Res Lett 29(19):1897. doi:10.1029/2002GL015373

Wu R, Hu ZZ, Kirtman BP (2003) Evolution of ENSO-related rainfall anomalies in East Asia and the processes. J Clim 16:3741-3757
Wu XW, Li JP, Jiang ZH, He JH (2010) Predictable climate dynamics of abnormal East Asian winter monsoon: once-in-a-century snowstorms in 2007/2008 winter. Clim Dyn 37:1661-1669

Xie SP, Hu K, Hafner J et al (2009) Indian Ocean capacitor effect on Indo-Western Pacific climate during the summer following El Niño. J Clim 22:730-747

Zhai PM et al (2005) Trends in total precipitation and frequency of daily precipitation extremes over China. J Clim 18:1096-1108

Zhang RH, Sumi A (2002) Moisture circulation over East Asia during El niño episode in Northern winter, spring and autumn. J Meteorol Soc Jpn 80:213-227

Zhang Y, Wallace JM, Battisti DS (1997) ENSO-like interdecadal variability: 1900-1993. J Clim 10:1004-1020

Zhang HQ, Qin J, Li Y (2011) Climatic background of cold and wet winter in southern China: part I observational analysis. Clim Dyn 37:2335-2354

Zhi XF, Zhang L, Pan JL (2010) An analysis of the winter extreme precipitation events on the background of climate warming in Southern China. J Trop Meteorol 16(4):325-332

Zhou LT (2011) Impact of East Asian winter monsoon on rainfall over southeastern China and its dynamical process. Int $\mathbf{J}$ Climatol 31:677-686

Zhou LT, Wu RG (2010) Respective impacts of the East Asian winter monsoon and ENSO on winter rainfall in China. J Geophys Res 115:D02107. doi:10.1029/2009JD012502

Zhou TJ, Yu RC (2006) Twentieth-century surface air temperature over China and the globe simulated by coupled climate models. J Clim 19:5843-5858

Zhou LT et al (2010) Influence of South China Sea SST and the ENSO on winter rainfall over South China. Adv Atmos Sci 27(4):832-844 